\title{
Article \\ Model for Assessing Information Logistics Systems in Banks: Lithuanian Case Study
}

\author{
Asta Valackiene *(D) and Rasa Andrijauskaite \\ Institute of Business and Economics, Faculty of Public Governance and Business, Mykolas Romeris University, \\ Ateities Street 20, Room C-V-509, LT-08303 Vilnius, Lithuania; rasa.andrijau@gmail.com \\ * Correspondence: asta.valackiene@gmail.com
}

Citation: Valackiene, A.;

Andrijauskaite, R. Model for

Assessing Information Logistics

Systems in Banks: Lithuanian Case Study. Logistics 2021, 5, 42. https:// doi.org/10.3390/logistics5030042

Academic Editors: Ieva

Meidutè-Kavaliauskienè and

Virgilija Vasilienè-Vasiliauskienè

Received: 26 April 2021

Accepted: 22 June 2021

Published: 28 June 2021

Publisher's Note: MDPI stays neutral with regard to jurisdictional claims in published maps and institutional affiliations.

Copyright: (c) 2021 by the authors. Licensee MDPI, Basel, Switzerland. This article is an open access article distributed under the terms and conditions of the Creative Commons Attribution (CC BY) license (https:// creativecommons.org/licenses/by/ $4.0 /)$.

\begin{abstract}
This study aims to provide valuable insights into the information logistics process and to ensure the effectiveness of its systems in the business environment by discussing the banking sector. In this regard, this study investigates the information logistics system of a bank's IT service center. For this purpose, the instruments for transfer of the bank $\mathrm{Z}$ information logistics system were empirically tested in order to highlight the assessment factors; the various factors related to the bank $\mathrm{Z}$ information logistics management methodologies and the methods were examined. The key findings and contributions were achieved, i.e., we developed a systematic model for assessing information logistics systems in a bank. The model explains the adaptation of various methodologies and techniques of information logistics systems in the banking sector and justifies the platform of interaction of information logistics processes. The first part of the article introduces the concept of information logistics systems and unpacks its development and management methodologies and processes. The second part introduces the research methodology for assessing information logistics systems. The results highlight the system of management processes applied to the information logistics and discuss the areas and tools for improving this system. The main outcome of this research is presented in the third part, where the systematic model for assessing information logistics systems is developed. This model distinguishes the stages of information logistics cycles and the levels of the information logistics environments. It indicates the information logistics methodologies and techniques linking to the six types of management processes in the IT service center of a bank. The developed model helps to make the assessment of the information cycle more efficient and demonstrates a customizable result which can be adapted by other companies within their IT service centers.
\end{abstract}

Keywords: information logistics system; assessment; management methods of process identification; model

\section{Introduction}

To understand the success of an organization seeking to ensure all business processes, including business quality, teamwork and leadership, professional optimization, and the effectiveness of information logistics processes, a holistic examination is needed on the discourse surrounding the interaction of various factors related to company management methodologies in terms of information logistics. In addition to this, it is important to emphasize the theoretical insights into the information logistics processes and to discuss the implementation of practical managerial knowledge relevant to the organization.

Researchers [1-7] have noted that information logistics systems are a subject analyzed both in Lithuania and globally. The importance of information management in the field of logistics has been emphasized. As one author [7] has stated, information handling within logistics leads primarily to the emergence of systems designed to ensure acquisition, flow and storage of information; further, these systems facilitate the appropriate realization of the primary and ancillary processes. 
The author of this paper argued that information logistics includes all types of logistics in a company. They emphasized the importance of information flows while highlighting the main problem of information logistics systems, i.e., the excess information, which has already become one of the main challenges for companies in gaining and maintaining their competitive advantage. From this point of view, it can be stated that the process of creating information requires data as one of the most crucial inputs, which justifies the inclusion of data as part of information logistics. These processes cannot be appropriately performed unless there is adequate equipment acquired for their realization, as well as appropriate technical and organizational solutions. Other scientists $[4,6,7]$ have extensively studied individual information logistics systems in particular companies and examined the links between logistics outsourcing, company competitiveness and information effectiveness [8]. Some articles have expanded the concept of a company's logistics processes through innovation [9] and have discussed the role of logistics information management [10] and a logistics strategy to achieve a company's performance [11,12].

Other researchers have stated [13] that companies have been using information technologies for the optimization of supply chain processes, where IT systems and analyses of large amounts of information and data are an irreplaceable thing. Some research papers have examined cloud computing for logistics and procurement services and the framework of cloud computing [12,14] with an emphasis on information logistics, discussing the level of information sharing and the security of shared information. This reliance promotes the creation of a new dimension of innovative logistics concepts. The relevant literature indicates that many practitioners and scientists have described the current situation as a logistics revolution, logistics 4.0 or logistics of the 21st century [7]. Some authors [15] have provided empirical results on logistics innovation capability and logistics operations at the level of a firm, justifying the interaction on innovation management and risk management in logistics. This concept offers original contributions to the logistics innovation, information management and supply chain risk management in the industry 4.0 era.

However, the authors of this paper found that the main criteria for evaluating information logistics systems are poorly described. Another important aspect to consider when studying information logistics is that, over the last three years, it has been emphasized that the significance of information logistics systems in companies has grown each year, but there is a lack of information logistics evaluation both conceptually and empirically, i.e., at the level of the specific (banking) company. Additionally, we would like to propose new insights for assessing the logistics of ICT processes and information cycles, which other companies can adapt within their IT service centers.

Furthermore, in our investigation, we justified three main dimensions for the concept of information logistics systems: (1) telematics as systems of data acquisition and transfer; (2) technical and organizational solutions using various methodologies and techniques (ITIL, COBIT, ISO; ServiceNow platform); (3) assessment of information logistics systems. In addition, we discussed how information logistics operate modern logistics strategies for growth and functioning in the bank's IT Service Center.

Moreover, we suggest that strategic analyses of the information logistics processes in the banking sector have not been performed in Lithuania. Therefore, it can be stated that the evaluation of a bank's information logistics system is performed inconsistently and without adhering to periodicity. However, the present literature examining the main characteristics of the information logistics methodologies and methods, how they can be implemented within companies in the banking sector, and how they can optimize the processes of information logistics, still has some shortcomings.

For this reason, the problems of information logistics systems are gaining more relevance, and in turn require a more detailed analysis.

This paper analyzes the information logistics system of a bank's IT service center. The theoretical insights were empirically tested by developing detailed research tools. A systematic model was constructed for the assessment of information logistics systems in banks. 
Accordingly, the aim of this paper is to identify and evaluate the instruments for transfer of the bank information logistics system, to discuss the advantages and disadvantages of these processes, and to develop a model for assessing information logistics systems in banks.

To summarize the level of scientific examination of this problem, it can be stated that our research is informed by the seminal theoretical insights into the management of information logistics systems [3-10,12,14-18] that are used to substantiate the systematic model for assessing information logistics systems in the IT service centers of banks.

Respectively, we suggest that the following research questions should be investigated:

- RQ1: 'How is the information logistics system of a bank evaluated using various methodologies and techniques (ITIL, COBIT, ISO)'?

- RQ2: 'What are the main advantages and disadvantages of the assessment of the bank's information logistics system, which were revealed by empirical research, in order to improve the information logistics processes'?

We conducted a qualitative study using the methods of content analysis of the bank's strategic documents and semi-structured interviews in order to establish a fact-based solution and to answer the proposed research questions.

Our research makes a number of contributions. Firstly, based on the theoretical analysis results, new theoretical insights corresponding to the methodologies for assessing information logistics systems in the banking sector have been highlighted. Secondly, the main research result was achieved, i.e., we developed a systematic model for assessing information logistics systems in banks. The model explains the adaptation of various methodologies and techniques of information logistics systems and justifies the platform of interaction of information logistics processes. The Model for Assessing Information Logistics Systems in Banks helps to streamline the information cycle and offers a practical result that allows other companies to adapt it within their own IT service centers.

\section{Contextual Framework of Information Logistics Systems in Banks}

\subsection{The Concept of Information Logistics}

When discussing the scope of the concept of information logistics, it is important to note its changes, from the transportation of products to the communication of information within the company, in order to ensure feedback not only in terms of the various logistics systems, but also between the consumer and these logistics systems. Wormley [19] was one of the first scholars to provide a definition of information logistics that considered it to be a management activity that facilitates product transportation and helps clients to grasp the information about goods and services that are in demand. He based his reasoning on the fact that information logistics aids the target consumers in duly obtaining the right set of information about products and services and, in turn, concluding successful business transactions. Klein [20] emphasized that logistics has multiple functions. It combines the business logistics and information management functions into a single system. It also ensures that the objectives of the company are achieved and that the operations across different teams in the same or separate company departments work smoothly. The author distinguished the key objectives of information logistics and discerned their significance in flow coordination by examining one of the information logistics objects, i.e., information flows in the supply chains. A short while later, the information logistics issues began to include the field of data transmission and protection. Tracking and information tracking became integral to the logistics services. Chaffe [21] and Deiters [22] emphasized that this type of logistics includes management of information, where it is considered a separate product. It highlights the importance of providing information that best corresponds with the requirements. Flensburg [23] is the pioneer of discussing information flows with regards to workflow modelling. Sandkuhl, Kutsche and Deiters [24] and Simonsen [25] developed a procedure for this kind of modelling and proposed that information supply and information flows are the main objectives of information logistics that are based on the requirements regarding the content of information, delivery time, presentation and quality. 
Laudon et al. [26] elaborated on the concept of information logistics by identifying the guidelines of information management processes, using Business Intelligence Tools. More recent authors [27] have emphasized that data flows are the components of information logistics that support decision-making processes. Other authors [28] extended the discussion about the significance of the logistics components and fleshed out the information logistics concept by highlighting the specific requirements for the information, i.e., the information product must be presented in the correct format, in the right place and time to the correct consumers, depending on their demand. Other authors [29] distinguished the underlying aspects of the information logistics objectives, namely, the optimized supply and flow of information in networking, regardless of the target groups and the information volumes.

Elaborating on the analysis of information logistics, some authors [2] distinguished 10 main directions: starting with the distribution of internal information; InformationProduction-Flow-Time; supply of the consumer needs information; information flow efficiency; interfunctional supply of analytical information; external information management; management of information flows in supply chains; information management in staff modelling; management of a global cross-referenced database; using information flows to improve processes. However, some authors [2] employed the four most commonly emphasized objects to elaborate on the analysis of the concept. They were examined using information logistics in order to eliminate the management issues of excess information and to allow for quality information flows in the company: supply of the consumer needs information; information flow efficiency; interfunctional supply of analytical information; using information flows to improve processes. One researcher [30] agrees with the opinions of the above authors but added a new aspect to the concept of information logistics. He identified the following methods to achieve the objectives: analysis of information demand; Intelligent Information Storage; optimization of information flows; ensuring technical and organizational flexibility; integrated information and payment solutions. Other researchers $[6,16,17]$ highlighted the efficient management of information logistics and concluded that information logistics functions as a connecting link of logistics systems with its own objective - to ensure and to coordinate the most optimal operating mode of each and every logistics system.

Some researchers [31] have drawn attention to the main aspects of logistics quality management system documentation preparation. They discussed quality management system documentation preparation models and document hierarchical systems, and analyzed QMS document logistics development processes.

In his discussion on the increased use and impact of the information and communications technology on business, one author [32] proposed that it is another component that substantiates the concept. That is, a significant result of the changes was an increased use of cloud computing services, which provides companies with the following advantages: efficiency and cost reduction; data security; the possibility to change the size of the company, whereby the company may efficiently and promptly expand or reduce its team depending on the needs of the business; the opportunity to increase cloud storage without any investment in a physical infrastructure; mobility that is enabled by the resources in the cloud that are easily stored, processed, received and restored; automatically implemented updates, which save time and reduce workloads allocated to system maintenance; restoration after emergencies, whereby cloud-based services provide a quick restoration of lost data after all types of emergency situations, including natural disasters and power outages. These services also enable more efficient control of data management.

Other authors [33] also mentioned the data mining process as a crucial process while processing numerous quantities of information containing relatively important data, whilst also taking into consideration the rapidly increasing tendency to shop online, which makes information quantities grow even more. While quantities are gradually increasing, information transmission becomes less smooth, which causes processes to fail. This tendency emphasizes the importance of information logistics and the current increasing demand. Ac- 
cording to the same authors, "logistics information is a general term reflecting knowledge, information, images, data and documents in various activities of logistics".

To sum up various theoretical insights, a logistics management information system (LMIS) can be understood as a system of records and reports-whether paper-based or electronic-used to aggregate, analyze, validate and display data (from all levels of the logistics system) that can be used to make logistics decisions and manage the supply chain. LMIS data elements include stock on hand, losses and adjustments, consumption, demand, issues, shipment status, and information about the cost of commodities managed in the system. LMIS constructs the links between different levels in the system through information, and provides the information each level needs to perform their supply chain role.

To illustrate the concept of information logistics, the authors of this study argued that, being integral in a management information system, a logistics information system has a special function to manage, control and measure the logistics activities in an organization. Linking this view with a more general understanding of the concept, we refer to the group of information management methods that are related to the automation and support of information systems in the process of management decision making.

The authors of this paper emphasized that information logistics and document management are closely associated with international ISO standards, being one of the most important aspects of the quality management system that can be applied to all companies.

\subsection{Characteristics of Information Logistics Methods in Banks}

The ability to successfully integrate an information logistics system into an organization is one of the most important strategic objectives of management processes. The authors of this study state that it is also important to understand the main characteristics of the information logistics methodologies and methods, how they can be implemented within companies in the banking sector, how they can optimize the processes of information logistics and how they can identify the potential sources of different issues.

To understand the efficiency of the internal processes, we examined various factors related to the bank's information logistics management methodologies and the methods described in our study. In order to understand how information logistics becomes an important part of the company's management system and how the system transforms the experience of information logistics management processes, we explored the theory and then illustrated in practice the description of the 'Information Logistics Methods' in a bank. We did this by analyzing the IT service center activities of bank $Z$ through the information logistics management experience, from the perspective of management science and information technology.

This part of the paper reveals how the information logistics methodologies, processes and methods could be applied in the IT service center of a bank. Accordingly, a detailed description of the methodologies and methods is provided.

The following information logistics methodologies are used in the IT service center of a bank: ITIL (Information Technology Infrastructure Library) —a service management methodology based on best practice; COBIT (Control Objectives for Information and related Technology) - good practice is aligned with good practice proposed by the international standards in the areas of IT management, service management, security and risk management; ISO 9001: 2015 (International Standard Organization)—a framework of quality management standards. These will be discussed in more detail in the article.

2.2.1. ITIL-Best Practice Service Management Methodology: Modules and Processes (Information Technology Infrastructure Library)

This methodology is focused on work optimization and ensuring quality in structures providing IT services. We describe several management process as found in the methodology libraries.

ITIL Best Practice Framework leads in Great Britain and in this position. Moreover, it is consistently improved with new versions being released regularly (ITIL1, 1989; ITIL2, 2001; ITIL3, 2007; ITIL 4, 2019). It is worth noting that, according to some authors [34], 
implementing ITIL methodology in an IT company is a long and sequential process that involves 11 steps: (1) an ITIL project draft, which requires a projection of long-term goals in order to ensure the internalization of ITIL principles; (2) defining the IT service structureconstructing a clear IT services view when developing the service structure; (3) ITIL roles and assigning them to individuals_-allocating persons responsible for executing the new ITIL processes; (4) analysis of existing processes-tracing the processes that do not require any changes and those that require urgent action; (5) defining the structure of the future process-identifying which ITIL process should be implemented in the company by presenting the structure/classification of the process (structure of the future process); (6) defining process links by identifying the limitations of the processes; (7) determining the management of the process - the persons responsible for the processes assess the operation of the process by following the objective quality criteria and key performance indicators, allowing for a possibility to decide whether improving the process is necessary; (8) detailed process planning - it is important to focus on the areas most pertinent to the company; (9) selection and implementation of the applied systems to ensure that new processes are supported; (10) implementation and training for the ITIL process-staff training is carried out; (11) performance analysis in order to determine the gains obtained by the company in implementing ITIL and which areas may be improved further.

Is it important to discuss the reasons for ITIL methodology evolution? The key aspect worth mentioning is the following: the new ITIL version states that a clear strategy is needed with regards to achieving company objectives, increasing the staff competencies, work efficiency, and increasing the quality of services in order to create better value for external and internal clients. Therefore, versions of the methodology have indeed evolved from the identification and IT infrastructure management (ITIL Version 1) to the requirements that IT services should be compatible with business requirements in order to ensure successful business operation and development (ITIL Version 4).

ITIL 4 view is based on the service value system, which is the main part of ITIL 4 that facilitates the creation of value. The service value chain (SVC) is an element of the service value system that describes the key cyclical operations required for the creation and presentation of products and services in order to meet the orders.

The ITIL 4 service value chain includes six operations: planning, involvement, projection and transition period, procurement/configuration, delivery support, and improvement. The chain demonstrates the way all organizational components operate together in the processes to create value.

Changes in the business environment stimulated a new aspect of quality in the ITIL 4 methodology: the key principles of service projection came to the fore and reflected the four dimensions that create value not only for clients, but also for the interested parties.

The new ITIL 4 version formulates recommendations for companies that are needed to solve new service management issues and offers 34 management practices. The ITIL 4 methodology contains various suggestions for each practice: key terms and concepts, success factors, key operations, information objects, etc. The 34 practices in this version are divided into three main categories: general management practice, service management practice, and technical management practice. This methodology, ITIL 4 (Version 4), is strongly focused on IT Operations Management systems and has three Practice Categorizations: General management practice, Service Management practice, Technical management practice [35].

2.2.2. COBIT-Methodology of Interaction/Collation of Good Practices and International Standards in IT, Services, Security and Risk Management: Modules and Processes Subsubsection

When discussing the methodology guidelines of COBIT, it should be noted that this standard was created by ISACA (Information Systems Audit and Control Association) and is known in many countries as a framework for IT security and control practices. In business, it is known through the acronym COBIT (Control Objectives for Information and related Technology). This framework of practices provides general principles on the 
manner in which the information system should be audited, including its control, security and management. There are seven versions of this methodology.

ISACA issued the first COBIT in 1996. In 1998, they published an improved second edition of this methodology. In 2000, they published the third edition, after which there were three more editions until the author presented the most recent COBIT edition in 2018 after a hiatus of seven years-namely COBIT 2019.

The latest COBIT 2019 version reinforces its role as a significant driver for innovation and business reform, and aids in securing the enterprise governance of IT (EGI), which is integral in company management. It also ensures efficiency by facilitating applied implementation. This methodology considers the latest technology, trends and enterprise security needs, including other IT governance methodologies, such as ITIL, ISO, etc. In this way, the methodology enables companies to incorporate all company processes. It also highlights risk management, information management and security. The methodology proposes a model which the governance agenda describes by way of 40 short-term governance and management objectives.

The latest COBIT system consists of four elements: (1) COBIT 2019 FrameworkIntroduction and Methodology, describing the structure of the methodology; (2) COBIT 2019 Framework-Governance and Management Objectives, presenting a detailed description of the main model and its 40 short-term objectives in terms of information governance and management; (3) COBIT 2019 Framework-Design Guide, proposing the best practices on how to integrate the existing COBIT 5 methodology with COBIT 2019; (4) COBIT 2019 Framework-Implementation Guide, proposing the guidelines on how to implement the methodology in practice.

The 40 short-term governance and management objectives discussed above are the components of the key model operation of this methodology (Source: according to ISACA, 2018).

2.2.3. ISO 9001: 2015-International Standard Organization Quality Management Systems: Certification for Logistics Quality Management

In support of successful change in logistics management processes, we encourage a wider understanding of the quality management system as exemplified by DAC/PAC (leadership $=$ the production of Direction/Purpose, Alignment and Commitment).

Taking this point into consideration, we discuss another methodology of information logistics that can be applied in the banking sector, ISO 9001: 2015, which is a logistics quality management certificate. Certification simply designates a company as being compliant with the standard 'ISO 9001-certified.' ISO 9001 states the requirements for the Quality Management System (QMS) in a company. ISO 9001 contains 10 Sections (clauses) with additional subclauses related to the Plan-Do-Check-Act system. Within the clause structure, a change to one section that increases the scope of the Quality Management System takes into account the organization's 'context' (for instance, social impact). The following Clause Structure Changes are observed in the document ISO 9001: 2015 (Section number: 1-10; Current Standard Sections, Proposed Standard Sections). The main differences in the Proposed Standard Sections are as follows: in Section 4, the general requirements are replaced with the context of the organization; in Section 5, Management Responsibility is replaced with Leadership; in Section 6, Resource Management is replaced with Planning; in Section 7, Product Realization is replaced with Support; in Section 8, Measurement, Analysis and Improvement is replaced with Operation; in Section 9, Performance Evaluation is provided-requirements for monitoring, measurement, analysis and evaluation are covered; in Section 10 under Improvement, the requirement for continual improvement has been extended to cover the suitability and adequacy of the QMS. (Source:/iso-9001-2015-requirements/iso-9001-2015-detail-structure).

The authors of the paper argued that it is important to discuss the way the certification process unfolds in a company when implementing the ISO 9001: 2015 quality standard.

The certification process has nine steps: (1) training/introduction to ISO 9001 ; (2) analysis of the limitations of the quality management system-identification of limitations with 
help from a consultant on quality; (3) development/restoration of the quality management system - the identified limitations of the system are corrected with appropriate procedures and systems; in cases where the company is newly established, a quality strategy for the company is created, which is then approved by the company's management, and a quality guide is produced that indicates the aims of the company seeking certification; (4) staff training on the standard of the quality management system-the quality management system is presented in individual sessions; (5) implementation of the quality management system-implementation of defined procedures that are generally monitored and maintained by the members of the quality team; (6) internal audit-a group of employees is selected and trained to audit company processes, and an audit plan is developed; (7) management review - a meeting is convened and the results of the review are distributed throughout the departments of the organization; (8) first phase audit/external audit is carried out by a certification authority that verifies the detailed preparation of the company, identifies potential problems for final certification and report submission; (9) certification audit, following the action plan that was drafted during the first audit; the certification document is awarded an ISO 9001 certificate valid for three years; however, certification consultants perform annual supervision and review.

In summary, it can be stated that ISO 9001:2015 methodology helps companies to adapt to the changing environment, to meet the expectations of their clients, and to determine the requirements of the quality management system by controlling the information logistics system.

\section{Assessment of Bank Information Logistics System}

\subsection{Research Methodology}

A qualitative study was chosen because it allows the evaluation of information logistics systems in companies, and because of the typology of knowledge associated with effective management. Documented methods deal with new experiences of implementation. Generally, studies that discuss change management usually employ the qualitative research method. Face-to-face, semi-structured interviews were considered the most suitable primary data collection tool to access this knowledge and to enable flexible, in-depth exploration of the issue.

Our research is based on a qualitative strategy, and mixed methods were applied (i.e., content analysis of the bank's internal strategic documents and semi-structured interviews). It follows a single case approach rather than the case itself, based on the intrinsic case study approach [36].

In order to achieve the aim of the research, we also specified the objectives: to identify the expression of the information technology system in the IT service center of a bank; and to substantiate the process cyclicality of information logistics systems, including IT services, security, service strategy, quality and risk management.

Purposive sampling was chosen as a non-probability sampling strategy. Purposive sampling was applied to find a bank that effectively manages the information logistics system at its IT Service center. Purposive sampling further corresponds to substantiation, i.e., the bank was selected according to these three qualitative criteria: firstly, it has been a leader for the last three years particularly in the field of information logistics-an international capital bank operating in Lithuania, in line with the research ethics, was coded as Z; secondly, the IT service center of this bank has employed the most employees in the finance sector; thirdly, a ServiceNow platform must be implemented as a strategic information management platform with the ensuing consequences for the bank's information logistics system. The IT service center of bank $Z$ is recognized as one of the fastest growing IT organizations in Lithuania.

In accordance with the ethics standards, the research anonymizes the name of the bank, thus identifying it as bank $Z$. The metrics of the analyzed documents are not given, and the bank representatives who participated in the research are not personally identified, but instead codified as I. 
The IT service center of bank Z was established in 2014 as the main IT department. Its purpose was to support digital financial solutions for the clients of the bank. A few years after being established, the IT service center became the fastest growing IT organization in Lithuania, which currently employs more than 1000 IT experts. This center is comprised of two main structural departments: IT Infrastructure and IT Development. The centre creates innovative solutions for future banking for private, business and institutional clients in Northern Europe. In recent years, the Lithuanian IT service center was recognized as the provider of the most unique services in Central and Eastern Europe (The Central and Eastern European Service Centers Awards, Warsaw, Poland, 2017).

Content analysis of the strategic documents and applied information logistics methods aided the achievement of the first objective of the research, i.e., assessing the advantages and disadvantages of the logistics system in the IT service center of the bank, by reflecting on the bank's strategy.

Analysis of the bank's internal documents (published performance results; position in the market; areas of improvement; articles noting the future objectives; daily, weekly, monthly, quarterly team performance reports and indicators) helped to identify the strategic development areas of the company.

Analysis of the strategic plans of the IT service center staff teams (adapted methodologies and schedules; newly implemented programs, processes and technical schedules) provided insight into the weak links of the services, and highlighted the strategic objectives of the company: (1) creating a flexible IT platform in the company that is designed to support innovations and to collect information resources; (2) assessing the Information Logistics System in order to increase staff productivity and to attract clients.

In order to make the information management system more efficient, it was proposed that an information management platform based on cloud computing should be used, namely ServiceNow, which is a software platform that supports IT service management and allows the automation of IT business management in accordance with the ITIL 3-4 methodology guidelines. The platform is focused on services related to tasks, operations and processes (in accordance with the ITIL 3-4 methodology guidelines). Machine learning is used in order to employ data and workflows to improve the speed of the modern company and to create the possibility of changing the company size. The implementation of the platform ServiceNow generated an excellent result and demonstrated high value: the platform provided complete visibility of the infrastructure and the services and a more efficient decision-making Configuration Management Database (CMDB) and control. A higher level of control and management was reached when implementing an integrated risk management program that helps to ensure a fast risk identification and response. The average time to restore services was reduced by $79 \%$, and the number of extremely significant incidents was reduced by $93 \%$. The standardization and consolidation of the bank's services to one platform allowed the bank's IT service center to continually improve opportunities and to digitize the information flows. The adaptation indicator of the new portal among the employees surpassed the expectations, reaching $90 \%$ in two weeks. By employing the modules offered by ServiceNow, such as Now Platform, staff experience was improved, thus providing an opportunity to move to a portal that manages all IT and information for the bank, which was not possible using previous toolsets. This platform created an option to automate error elimination and allowed the accurate measurement of the efficiency of security processes. It should be noted that an important linkage of security processes with operational processes enabled a more effective internalization of the IT4IT reference architecture. The implemented ServiceNow platform became a strategic information management platform for bank $Z$, which allowed a more efficient management of data, services and risk effectiveness, as well as creating a better employee experience. This platform became the backbone of the bank, supporting all future implementations, integrations and innovations. This product both improved performance productivity and increased client satisfaction with regards to them obtaining information quickly. 


\subsection{Data Collection and Analysis: Semi-Structured Interview}

The data obtained from the instrumental case study by analyzing strategic documents were verified through the method of a semi-structured interview, which triangulated the information, i.e., it allowed us to verify it.

Our primary data consists of the transcripts of seven semi-structured interviews with the Team IT service center (the entire team comprised seven members); all informants were chosen from the organization within the case study object, i.e., bank Z's IT service center team members responsible for the operation, supervision, control and problem solving related to the processes in the information logistics system of the center.

All interviews were carried out within a month of the launch of the change initiative in the information logistics system that applied the cloud computing information management platform ServiceNow. The majority of informants reported their experiences concerning their engagement with or exposure to this change initiative.

The responses of the informants $(\mathrm{N}=7)$ were codified as I in the following way: I1, I2, I3, . , I7. During the interview, the focus was on improving the information logistics system of the IT service center of bank Z by reflecting on the bank's strategy and by increasing the efficiency of the information logistics system operations.

The semi-structured interviews consisted of 10 open-ended questions that were formulated with reference to the concepts discussed in the article. The authors emphasized that the main dimension of the interview focused on the areas of improvement in the information logistics system of the bank's IT service center. Based on this dimension, the interview was constructed by drawing three scenarios: (1) the expression of the processes taking place in the information logistics system in the bank's IT service center; (2) the limitations of the information logistics system in the bank's IT service center; (3) the areas of improvement of the information logistics system in the bank's IT service center.

During the semi-structured interviews, change recipients and the informants who experienced changes were invited to discuss their stories regarding how they were introduced to the change initiative in the information logistics system; their role, activities and experience in this initiative; and their application of the information management platform ServiceNow.

The first scenario was based on a research criterion in order to identify the existing processes of the information logistics system in the IT service center of the bank. Verification used the following indicators: the conception of the functionality of the information logistics system and the discussion of its processes (e.g., IT services, security, risk and quality management processes). The first scenario is developed in questions 1-3.

The second scenario helped to identify the limitations of the information logistics system management in the IT service center of the bank. This was based on the research criterion concerning the identification and improvement of management processes of the information logistics system in the IT service center of the bank. Verification used the following indicators: cyclicality of the existing management process and identification of the limitations of the existing information logistics system in the IT service center of the bank. The second scenario is developed in questions 4-6.

The third scenario allowed the researchers to emphasize the areas of improvement of the information logistics system in the IT service center of the bank and, in turn, to support the following research criterion: verifying the systematic model, i.e., verifying the significant interaction between the elements of the model structure by developing this scenario in questions 7-10.

Each interview lasted from one hour to an hour and a half. After analyzing the collected data, the informants were asked to review the findings and to provide comments.

We analyzed the data using a modified version of content analysis. The qualitative content analysis distinguished the following categories: factors of a successfully functioning system; responsibility for system processes; frequency of system review and certification; frequency of system updates; system limitations and solutions; signs of system inefficiency; factors influencing the significance of the system; system management methodologies; 
system supervision; system obstacles when implementing management methodologies. The categories were further divided into subcategories that facilitated the assessment of the technical and human factors concerning the information logistics system that are conditions for the successful functioning of the system. These subcategories also defined the roles of the system owner: they defined the system owner's and the team's responsibility for the system processes, and the regularity of maintenance and updates. They identified the limitations of the system and the possible solutions with an aim to eliminate the signs of inefficiency both in terms of the consumers and the system itself. The subcategories also facilitated the elimination of technical, financial and human capital obstacles.

Drawing on the semi-structured interview, we can state that ' $<\ldots$ the successful functioning of the information logistics system in the IT service center of the bank is conditioned not only by technical factors, but also human factors' (I1-I5); '< . . > the information logistics system in the IT service center of the bank is updated at different speeds' (I2-I7); '< . . > The speed of information distribution, the control of information, security, convenient usage, clarity of information, documentation, detailed guidelines'(I4-I5). When discussing the limitations of the system and their solutions, everyone noted that they ' $<\ldots>$ do not have a unified model for distributing information, therefore there is a lack of a flow' (I7-I7); '< . . > cost savings, a need for higher efficiency, market changes demand faster changes in the internal implementation whilst maintaining a high quality of these changes. Furthermore, there is a need for ensuring stronger communication between different departments by clearly assigning responsibilities'. The triangulation of the semi-structured interview is presented in Table 1.

Table 1. Triangulation Findings of the Semi-structured Interview Content Analysis.

\begin{tabular}{|c|c|c|c|}
\hline Research Criteria & $\begin{array}{c}\text { Categories/Subcategories Reflect } \\
\text { Survey Indicators }\end{array}$ & Repetition Rate & Interview Quotes \\
\hline \multirow{6}{*}{$\begin{array}{l}\text { expression of the information } \\
\text { logistics system processes in the } \\
\text { IT service center of the bank }\end{array}$} & \multirow{3}{*}{$\begin{array}{l}\text { Factors of a successfully } \\
\text { functioning system }\end{array}$} & 4 & $'<\ldots>$ consumer accessibility and convenience'; \\
\hline & & 3 & $\begin{array}{c}'<\ldots>\text { applying the best practices of product } \\
\text { development and testing'; }\end{array}$ \\
\hline & & 4 & $\begin{array}{c}\text { '< . . > regular process review and unified } \\
\text { application of methodology across the } \\
\text { organization' }\end{array}$ \\
\hline & \multirow[b]{2}{*}{$\begin{array}{l}\text { Responsibility for system } \\
\text { processes }\end{array}$} & 4 & ' $<\ldots>$ these are the owners of each process'; \\
\hline & & 2 & $\begin{array}{c}\text { '< . . > the responsibility for each system } \\
\text { component is assigned to individual } \\
\text { departments and their staff'; }\end{array}$ \\
\hline & $\begin{array}{l}\text { Frequency of system review and } \\
\text { certification }\end{array}$ & 3 & $'<\ldots>$ annually'; \\
\hline \multirow{6}{*}{$\begin{array}{l}\text { limitations of the information } \\
\text { logistics system in the IT service } \\
\text { center of the bank }\end{array}$} & Frequency of system updates & 4 & $\begin{array}{l}\text { '< }<\ldots>\text { the system is supplemented and its } \\
\text { functionality improved each week, whereas } \\
\text { substantial system changes (e.g., changes to the } \\
\text { version) are made twice a year'; }\end{array}$ \\
\hline & \multirow{3}{*}{ System limitations and solutions } & 2 & $'<\ldots>$ not very user-friendly'; \\
\hline & & 3 & $\begin{array}{l}\text { '<...> a large number of information flows, the } \\
\text { information is widely spread out, there is no one } \\
\text { resource that is 'guaranteed', therefore searching } \\
\text { for information is complicated, it is unclear who } \\
\text { the owners of the information are and who the } \\
\text { responsible persons for updates are, a large } \\
\text { number of databases, information duplicates'; }\end{array}$ \\
\hline & & 2 & $\begin{array}{c}'<\ldots>\text { we looked for the solution by changing } \\
\text { the IT infrastructure and by optimizing the } \\
\text { application itself'; }\end{array}$ \\
\hline & \multirow[b]{2}{*}{ Signs of system inefficiency } & 4 & $'<\ldots>$ from consumer feedback'; \\
\hline & & 3 & $\begin{array}{c}\text { ' }<\ldots>\text { the search for information in the systems } \\
\text { is long, difficulties in finding information, many } \\
\text { different sources'; }\end{array}$ \\
\hline
\end{tabular}


Table 1. Cont.

\begin{tabular}{|c|c|c|c|}
\hline Research Criteria & $\begin{array}{c}\text { Categories/Subcategories Reflect } \\
\text { Survey Indicators }\end{array}$ & Repetition Rate & Interview Quotes \\
\hline \multirow{8}{*}{$\begin{array}{l}\text { areas of improvement in the } \\
\text { information logistics system in } \\
\text { the IT service center of the bank }\end{array}$} & \multirow{3}{*}{$\begin{array}{l}\text { Factors influencing the } \\
\text { significance of the system }\end{array}$} & 2 & $\begin{array}{l}\qquad<\ldots>\text { a need to share information between } \\
\text { different departments, to coordinate actions and } \\
\text { to obtain feedback'; }\end{array}$ \\
\hline & & 2 & $'<\ldots>$ extremely fast market changes'; \\
\hline & & 1 & 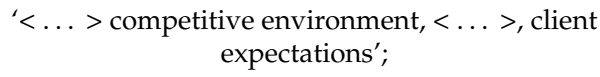 \\
\hline & $\begin{array}{l}\text { System management } \\
\text { methodologies }\end{array}$ & 6 & $\begin{array}{c}'<\ldots>\text { yes, everything is being built upon the } \\
\text { ITIL methodology'; }\end{array}$ \\
\hline & \multirow[t]{2}{*}{ System maintenance } & 2 & $\begin{array}{c}\text { '< . . > operations for supporting, updating and } \\
\text { improving the infrastructure and the applied } \\
\text { software are being carried out.' }\end{array}$ \\
\hline & & 2 & $\begin{array}{c}'<\ldots>\text { a respective team that supervises it as its } \\
\text { own product'; }\end{array}$ \\
\hline & \multirow[t]{2}{*}{$\begin{array}{l}\text { System obstacles when } \\
\text { implementing management } \\
\text { methodologies }\end{array}$} & 3 & $\begin{array}{l}\text { '<.. > when implementing new methodologies } \\
\text { or new versions, the most difficult thing is to test } \\
\text { whether everything works in accordance with } \\
\text { the current processes and whether there will be } \\
\text { any logical or technical obstacles.'; }\end{array}$ \\
\hline & & 1 & '< . . > limited costs'; \\
\hline
\end{tabular}

\section{Model for Assessing Information Logistics Systems}

The authors of this paper argue that while information logistics systems are already successfully applied within organizations, deploying this system and discussing the crossorganizational applications of it on an interdisciplinary level may still be of interest in academic research: How can the developed process model be employed to better design the information logistics processes in organizations? How can we improve the assessment of the information logistics processes in the banking sector in terms of applying information logistics methodologies and techniques?

In order to achieve a comprehensive picture of the efficiency of the information logistics systems, all processes must be planned simultaneously, including the requirements, capacities, methodologies, techniques and evaluation processes.

In accordance with the results and the theoretical insights with regards to the research questions (Q1: 'How is the information logistics system of a bank evaluated using various methodologies and techniques (ITIL, COBIT, ISO)?' and Q2: 'What are the main advantages and disadvantages of the assessment of the bank's information logistics system, which were revealed by empirical research, in order to improve the information logistics processes?'), the authors summarized the instrumental case study data and proposed that the solution to the scientific problem had been reached.

The formulated Model for Assessing Information Logistics Systems in IT Service Centers of Banks (Figure 1) helped to make the company's information cycle more efficient and has an applied result, which will also enable other companies with IT service centers to use it.

The model was constructed as a systems model that allows a holistic approach to information logistics systems. The model explains how various methodologies and techniques of information logistics systems can be applied, and creates a basis for the interaction platform of the information logistics processes. To obtain a comprehensive picture when assessing the effectiveness of information logistics systems, we demonstrated how the three environments of an information logistics system interact (i.e., external and internal environments and the IT service center of the bank). The model explains the interaction of the main environments of the information logistics system, and distinguishes the stages of information logistics cycles as well as the levels of the information logistics environments. It indicates the information logistics methodologies and techniques linking to the six types 
of management processes in the IT service center of the bank. It can be stated that these environments (IT service management processes, external environment of the information logistics system, internal environment of the information logistics system) closely interact and are explained cyclically in the system, ensuring the continuity and sustainability of the entire information logistics system. The external environment of the information logistics system helps to enable and manage external factors (e.g., the competitive environment, economic factors, customer and market conditions); the internal environment of the information logistics system allows the functioning and management of the services provided by the bank's IT service center (e.g., the internal information flows and factors, as well as the cycle of IT service management processes); the field of information logistics management in the IT service center indicates the expression of the logistics processes resulting from each structural part and identifies the system hosts, who follow the guidelines of the specific methodologies and techniques (it functions cyclically, explains the actions of the information system owners and the way the IT service management processes work in the bank).

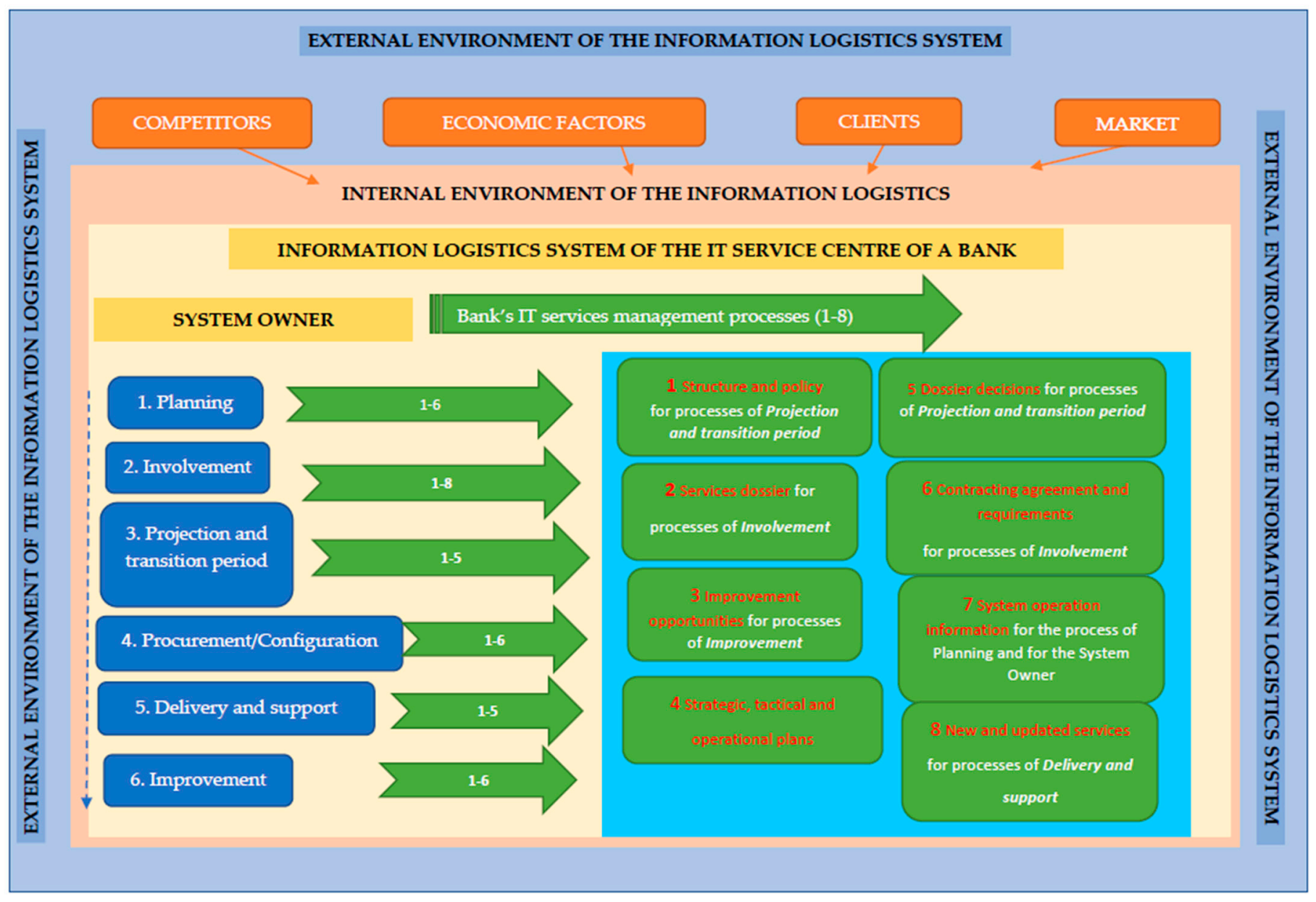

Figure 1. Model for assessing information logistics systems in a bank.

The following are the three structural parts (I, II, III) illustrating the management processes that interact with each other, and the processes explaining each part, where structural elements and interactions are justified:

I IT services management processes explains all System Owner processes (1-6) in the system cyclically: (1) Planning; (2) Involvement, (3) Projection and transition period; (4) Procurement/Configuration; (5) Delivery and support; (6) Improvement. 
1. Planning (ensures a general understanding of the vision, current situation, areas of improvement in all processes across the company): strategic, tactical and operational plans are discussed; decisions are made for the processes Projection and transition period; structure and policy for the processes of Projection and transition period; improvement opportunities for the processes of Improvement; services dossier for the processes of Involvement; contracting agreement and contract requirements for the processes of Involvement.

2. Involvement (guarantees the needs of the interested parties, ensures transparency and supports consistent involvement): requirements and opportunities for the processes of Planning; service requirements for the processes of Projection and transition period; consumer support tasks for the processes of Delivery and support; improvement opportunities and feedback from interested parties for the processes of Improvement; requests for updates and project initiatives for the processes of Procurement/configuration; Contracting agreements and contracts with external and internal suppliers and partners for the processes of Projection and transition period and Procurement/configuration; knowledge and information about the components of the third party services; customer service performance reports.

3. Projection and transition period (ensures that the services consistently meet the expectations of the interested parties with regards to the quality, costs and delivery time to the consumers): requirements and specifications for the processes of Procurement/configuration; contracting agreement and contract requirements for the processes of Involvement; new services for the processes Delivery and support; knowledge and information about new and updated services for all processes; information about the functioning and opportunities for improvement for the processes of Improvement.

4. Procurement/configuration (ensures that service components meet the agreed specifications): service components for the processes Delivery and support; service components for the processes Projection and transition period; knowledge and information about new and changed service components for all processes; contracting agreement and contract requirements for the processes of Involvement; information about the functioning and opportunities for improvement for the processes of Improvement.

5. Delivery and support (ensures that the service functions in accordance with the expectations of the interested parties): services delivered to the consumers; information for the processes of Involvement about the performance of the consumer support tasks; information about service functioning for the processes of Improvement and Involvement; contracting agreement and contract requirements for the processes of Involvement; requests for updates for the processes of Procurement/configuration.

6. Improvement (ensures a consistent service improvement in all operations of the company): improvement initiatives for all system processes; information on system functioning for the process of Planning and for the service owner; information on service provision for the processes of Projection and transition period; reports on the service performance improvement status; contracting agreement and contract requirements for the processes of Involvement.

II External environment of the information logistics system that enables the effect of external factors (covering the external aspects): Competitors, Economic Factors, Clients, Market to the IT services, which are conditioned by the competitive environment, economic factors and market conditions.

III Internal environment of the information logistics system, where the services provided by the IT service center of the bank function (covering the IT service center of the bank, the internal factors influencing it, and the management process cycle of IT services), and described service management processes (1-8): (1) Structure and Policy 
for processes for Projection and Transition Period; (2) Services Dossier for processes of Involvement; (3) Improvement Opportunities for processes of Improvement; (4) Construct Strategic, Tactical and Operational Plans; (5) Dossiers Decisions for processes of Projection and Transition Period; (6) Contracting Agreements and Requirements for processes of Involvement; (7) System Operation Information for the process of Planning and for the System Owners; (8) New and Updated Services for processes of Delivery and Support.

Illustration of the Model (Figure 1). The structural parts illustrate the way the IT service management processes cyclically function in order to ensure the continuity of the system, the way information logistics system environments interact with each other (external, internal, IT service center of the bank), the actions of the system owners, and the way the IT service management processes operate. The constructed model reveals the expression and cyclicality of IT service management processes (planning, engagement, design and transition period, acquisition/configuration, delivery and support, improvement). The links to external and internal information logistics system environments are evaluated. External factors are enabled to operate externally (the external field of the IT service, which is determined by the competitive environment, economic factors, and customer and market conditions). The services provided by the bank's IT service center function in the internal environment of the information logistics system (the bank's IT service center, the efficiency of which is based on the internal factors influencing it and ensures the cycle of IT service management processes). Each IT service management process specifies specific process outputs. The structural parts of the model note the never-ending continuity of IT service management processes.

The originality of the model is characterized and demonstrated in two sets; first of all, conceptually (i.e., as a new scientific solution, since no systematic model designed specifically for the IT sector of the bank is found in scientific literature), as the information logistic management of the IT service center. This helps to answer the question conceptually: How can the assessment of information logistics processes in the banking sector be improved in relation to the use of information logistic methodologies and methods? A description of the design of the model and its detailed structure are given. This is a truly useful and interesting conceptual result. Secondly, at its applied/practical level: the basis of this investigation and the existing practice can be used by other practitioners. Reflecting on the practical-position question that the process model created can be applied in other organizations in the banking sector's IT service center in order to design and manage information logistics processes more efficiently.

Both of these aspects (conceptual and practical experiences) also highlight the specificity of the developed model. The model is developed for a specific sector (banking sector), for efficient management of the bank's IT information logistics.

There is a limitation of the model; of course, we can to expand the service management processes (1-8) in the model design/figure as much as possible, but in the authors' opinion, it would have been even more loaded on the figure. The authors draw the attention of readers to the fact that all banks' IT service management processes are described in detail when presenting the structure of the model.

\section{Discussion and Conclusions}

This study discusses information logistics systems by combining normative discourse and explanatory discourse to substantiate the consensus and continuity of the analysis of the social phenomenon. The authors developed an interdisciplinary discourse, thus creating a space for the input from other researchers in the wider debate. Therefore, it is an indisputable fact that information is vital to a business, especially the banking sector. For this reason, our research makes a number of contributions. Key findings: The model for assessing information logistics systems in banks was constructed. At this point, we stated that the importance of information management in the field of bank logistics is emphasized, stating that information handling within logistics leads primarily to the emergence of 
systems designed to ensure acquisition, flow and storage of information; further, these systems facilitate appropriate realization of the primary and ancillary processes. In this context, the idea has been developed that the data required for the information creation process is one of the most important contributions, which justifies the inclusion of data as part of the information logic. These processes cannot be carried out properly unless the right equipment is acquired and the right technical and organizational solutions are implemented.

This study provides valuable insights into the information logistics process and seeks to ensure the effectiveness of its systems in the business environment by discussing the banking sector. In this regard, the study investigates the information logistics system of a bank's IT service center, where different information logistics methodologies, methods and instruments were applied, by arguing how they can be implemented in the banking sector, highlighting how they can optimize the processes of information logistics in banks and identify the potential sources of different issues. For this purpose, the instruments for transfer of the bank $Z$ information logistics system were empirically tested in order to highlight the assessment factors; the various factors related to the bank $\mathrm{Z}$ information logistics management methodologies and the methods were examined. We did this by analyzing the IT service center activities of bank $\mathrm{Z}$ through the information logistics management experience from the perspective of management science and information technology.

In order to understand how information logistics becomes an important part in a company's management system, we explored the theory. Furthermore, in our investigation, we justified three main information logistics system concept dimensions: (1) telematics as systems of data acquisition and transfer; (2) technical and organizational solutions using various methodologies and techniques (ITIL, COBIT, ISO; ServiceNow platform); (3) evaluation of information logistics systems.

The article highlights the theoretical insights related to the information logistics systems and processes and their practical applications-the description of the 'Information Logistics Methods' in a bank illustrated in practice. We substantiated the theoretical and practical aspects of developing and evaluating information logistics systems by applying the QMS documentation development process and selecting other appropriate models, methodologies and techniques: ITIL (Information Technology Infrastructure Library) - a service management methodology based on best practice; COBIT (Control Objectives for Information and related Technology) - good practice is aligned with good practice proposed by the international standards in the areas of IT management, service management, security and risk management; ISO 9001: 2015 (International Standard Organization)-a framework of quality management standards; and ServiceNow—an information management platform based on cloud computing. We prepared information maps and procedures for the bank's logistics processes that will form the basis for the successful implementation and management of the quality management system.

The results of the conceptual analysis highlighted a new theoretical insight, justifying three information logistics system concept dimensions: telematics, technical and organizational, evaluation of information logistics systems into the assessment methodologies of information logistics systems in the banking sector. The main outcome of the study is the development of the systematic model for assessing information logistics systems in banks. The idea to develop a systematic model for assessing information logistics systems came as a response to the fact that organizational management predominantly relies on models that often provide limited results. Over the last three years, it has been emphasized that the significance of information logistics systems in companies has grown each year. However, strategic analyses of the information logistics processes in the banking sector have not been performed in Lithuania.

Based on the above insights and research results, the model for assessing information logistics systems can now be built as a complex systems model. The model is constructed as a systems model that allows for a holistic approach to information logistics systems. 
The model explains how various methodologies and techniques of information logistics systems can be applied and creates a basis for the interaction platform of the information logistics processes. To obtain a comprehensive picture when assessing the effectiveness of information logistics systems, we demonstrated how the three environments of an information logistics system interact (i.e., external and internal environments and the IT service center of the bank). The model explains the interaction of the main environments of the information logistics system and distinguishes the stages of information logistics cycles as well as the levels of the information logistics environments. It indicates the information logistics methodologies and techniques linking to the six types of management processes in the IT service center of the bank.

We noted that these environments closely interact to ensure the continuity and sustainability of the entire information logistics system. The external environment of the information logistics system helps to enable and manage external factors (e.g., the competitive environment, economic factors, customer and market conditions); the internal environment of the information logistics system allows for the functioning and management of the services provided by the bank's IT service center (e.g., the internal information flows and factors, as well as the cycle of IT service management processes); the field of information logistics management in the IT service center indicates the expression of the logistics processes resulting from each structural part and identifies the system hosts, who follow the guidelines of the specific methodologies and techniques (it functions cyclically, and explains the actions of the information system owners and the way the IT service management processes work in the bank).

The model for assessing information logistics systems helps to streamline the information cycle and offers a practical result that allows other companies to adapt it within their own IT service centers.

In the literature review, conducted at the beginning of this study, we could not find a study examining information logistics in the banking sector in the context of assessing information logistics systems. In this respect, we believe that the research model established in our research is original, and we hope that this study will be an essential contribution to the existing literature. We also believe that the findings of the study will benefit scientific debate.

Research limitation and future research directions: The conducted qualitative research revealed a depth of knowledge and valuable insights into the information logistics processes and explored the effectiveness of its systems in the business environment by discussing the banking sector. Nonetheless, it faced some limitations: there were seven informants only. Due to the more generalized results and conclusions, more study participants need to be involved. Therefore, the authors plan to expand the study in the future. Furthermore, for future research, it would be useful to have a new case study research conducted that would provide more specific data.

Author Contributions: Conceptualization, A.V. and R.A.; methodology, A.V.; validation, A.V.; formal analysis, A.V. and R.A.; investigation, A.V. and R.A.; writing-original draft preparation, A.V. and R.A.; writing-review and editing, A.V.; visualization, A.V. and R.A.; supervision, A.V. All authors have read and agreed to the published version of the manuscript.

Funding: This research received no external funding.

Institutional Review Board Statement: Not applicable.

Informed Consent Statement: Not applicable.

Data Availability Statement: Not applicable.

Acknowledgments: The authors acknowledge the reviewers' and editors for valuable comments directed at improving the quality of the manuscript.

Conflicts of Interest: The authors declare no conflict of interest. 


\section{References}

1. Al Salaimeh, S. A new model for information logistics system Architecture. J. Theor. Appl. Inf. Technol. 2011, $28,39-47$.

2. Haftor, D.; Kajtazi, M.; Mirijamdotter, A. A Review of Information Logistics Research Publications. Lect. Notes Bus. Inf. Process. 2011, 97, 244-255. Available online: https://www.researchgate.net/publication/221281792_A_Review_of_Information_ Logistics_Research_Publications (accessed on 25 November 2019).

3. Zinkevičiūtè, V.; Vasiliauskas, A.V. Gamybos logistika. Gamybos vadyba. Klaipèda: S. Jokužio Leidykla-Spaustuvė. 2013. Available online: http://www.marko.lt/wp-content/uploads/2016/09/2013_Gamybos_logistika_Gamybos_vadyba.pdf (accessed on 23 October 2019).

4. Szmelter, A. Business intelligence jako element ntern zaopatrzenia informacyjnego [Business Intelligence as an Element of the Information Supply System]. Res. Ann. WSB Univ. Toruń 2013, 12, 129.

5. Altendorfer-Kaiser, S. Information Logistics Means to Support a Flexible Production? In IFIP International Conference on Advances in Production Management Systems; Springer: Cham, Switzerland, 2015; pp. 414-421. Available online: https://www.researchgate. net/publication/300569206_Information_Logistics_Means_to_Support_a_Flexible_Production (accessed on 25 November 2019).

6. Sandkuhl, K. Selected Topics on Information Logistics: Editorial Introduction to the Issue 2 of CSIMQ. Complex Syst. Inform. Modeling Q. 2015, 2. Available online: https:/ / www.researchgate.net/publication/276156387_Selected_Topics_on_Information_ Logistics_Editorial_Introduction_to_the_Issue_2_of_CSIMQ (accessed on 26 November 2019). [CrossRef]

7. Weiland, D. Identifying the impact of information logistics on contemporary conceptions of logistics. Transp. Econ. Logist. 2018, 78, 167-177. [CrossRef]

8. Afum, E.; Agyabeng-Mensah, Y.; Acquah, I.S.K.; Baah, C.; Dacosta, E.; Owusu, C.S.; Amponsah Owusu, J. Examining the links between logistics outsourcing, company competitiveness and selected performances: The evidence from an emerging country. Int. J. Logist. Manag. 2021, ahead-of-print. [CrossRef]

9. Pinchuk, T.O.; Chuvashova, N. Concept of logistics processes in the activity of a construction company in the implementation of innovative construction projects. IOP Conf. Ser. Mater. Sci. Eng. 2020, 880, 012115. [CrossRef]

10. Lyu, G.; Chen, L.; Huo, B. The impact of logistics platforms and location on logistics resource integration and operational performance. Int. J. Logist. Manag. 2019, 30, 549-568. [CrossRef]

11. Khan, S.; Rattanawiboonsom, V.R. The role of logistics strategy on firm performance of garment industry in Bangladesh. Int. J. Logist. Syst. Manag. 2020, 37, 540-555. [CrossRef]

12. Supansa, C.; Haasis, H.D. Cloud computing for logistics and procurement services for SMEs and raw material suppliers. Int. J. Logist. Syst. Manag. 2021, 38, 459-474.

13. Meidutè-Kavaliauskienè, I.; Yıldız, B.; Çigdem, S.; Činčikaitè, R. An Integrated Impact of Blockchain on Supply Chain Applications. Logistics 2021, 5, 33. [CrossRef]

14. Ragmani, A.; El Omri, A.; Abghour, N.; Moussaid, K.; Rida, M. A global performance analysis methodology using Taguchi approach: Case of cloud computing and supply chain. Int. J. Logist. Syst. Manag. 2020, 37, 252-284. [CrossRef]

15. Wang, M.; Asian, S.; Wood, L.; Wang, B.C. Logistics innovation capability and its impacts on the supply chain risks in the Industry 4.0 era. Mod. Supply Chain Res. Appl. 2020, 2, 83-98. [CrossRef]

16. Meidutè, I. Logistikos Sistema, Vilniaus Gedimino Technikos Universitetas; Technika: Vilnius, Lithuania, 2012.

17. Oržekauskas, P. Informacinès Logistikos Pagrindai (Metodinè Priemonè); Technologija: Kaunas, Lithuania, 2009.

18. Rudzajs, P.; Kirikova, M. Conceptual Correspondence Monitoring: Multimode Information Logistics Approach. Complex Syst. Inform. Modeling Q. 2014, 1. Available online: https://www.researchgate.net/publication/261288373_Conceptual_Correspondence_ Monitoring_Multimode_Information_Logistics_Approach (accessed on 25 November 2019). [CrossRef]

19. Wormley, P.W. Information logistics: Local distribution (delivery) of information. J. Q. 1978, 55, 635.

20. Klein, S. Information Logistics. EM Electron. Mark. 1993, 9-10. Available online: https://pdfs.semanticscholar.org/8c50/196fd8a6 90d10cf52a89dfc0b0d5d1f41d77.pdf (accessed on 21 October 2019).

21. Chaffe, B.C. Information Logistics: Outsourcing Solutions Can Improve Productivity. White Paper; Graduate School of Business, University of Washington: Seattle, WA, USA, 2001.

22. Heuwinkel, K.; Deiters, W. Information Logistics, E-Healthcare and Trust, Dortmund; Institute for Software and Systems Engineering: Dortmund, Germany, 2003.

23. Flensburg, P. Information logistics and content management-Buzzwords or important concepts. In Knowledge Spillovers and Knowledge Management, Cheltenham, Edward Elgar; Karlsson, C., Flensburg, P., Hörte, S.-Å., Eds.; Edward Elgar Publishing: Cheltenham, UK, 2004; pp. 479-492.

24. Haseloff, S. Context Gathering-an Enabler for Information Logistics. In Knowledge Supply and Information Logistics in Enterprises and Networked Organizations, Proceedings of the International Workshop Associated with the Multi-Conference on Wirtschaftsinformatik of the Gesellschaft für Informatik e.V; Deiters, W., Kutsche, R.D., Sandkuhl, K., Eds.; University of Duisburg-Essen: Duisburg, Germany, 2004.

25. Simonsen, G.H. The Global Cross-Reference Data Base-A Tool for Information Logistics in e-Business. In Proceedings of the Fifth eGov-Conference, Copenhagen, Denmark, 22-26 August 2005; University of Antwerpen: Antwerp, Belgium, 2005 ; pp. 635-645.

26. Laudon, K.; Laudon, J. Management Information Systems: Managing the Digital Firm, 9th ed.; Prentice Hall: Upper Saddle River, NJ, USA, 2006. 
27. Winter, R. Enterprise-wide Information logistics: Conceptual Foundations, Technology Enablers, and Management Challenges. In Proceedings of the ITI 2008 30th International Conference on Information Technology Interfaces, Cavtat, Croatia, 23-26 June 2008; p. 41.

28. Olthof, W.; de Haan, J.; Willems, J. Information Logistics, White Paper; NRG/Nashuatec Benelux: Breukelen, The Netherlands, 2008.

29. Hakansson, A.; Hartung, R. Agent and Multi-Agent Systems: Technologies and Applications. In Proceedings of the Third KES International Symposium, KES-AMSTA, Uppsala, Sweden, 3-5 June 2009.

30. Uckelmann, D. Performance Measurement and Cost Benefit Analysis for RFID and Internet of Things Implementations in Logistics. In Quantifying the Value of RFID and the EPCglobal Architecture Framework in Logistics; Springer: Berlin/Heidelberg, Germany, 2012.

31. Šaulinskas, L.; Paliulis, N.K.; Meidutè-Kavaliauskienè, I. Theoretical and Practical Aspects of Logistic Quality Management System Documentation Development Process. Contemp. Econ. 2013, 7, 57-72. [CrossRef]

32. Bozicevic, V. Cloud Computing Benefits: 7 Key Advantages for Your Business. 2018. Available online: https://www.globaldots. com/blog/cloud-computing-benefits (accessed on 7 December 2019).

33. Qingyuan, Z.; Zongming, Z.; Yuancong, W. Research on safety management system optimization of B2C e-commerce intelligent logistics information system based on data cube. J. Intell. Fuzzy Syst. 2019, 38, 1-8.

34. Kempter, A.; Kempter, S. The ITIL Process Map. 2013. Available online: https://en.it-processmaps.com/products/itil-processmap.html (accessed on 8 December 2019).

35. ITIL Foundation. ITIL 4th Edition; AXELOS LIMITED: London, UK; The Stationery Office: London, UK, 2020 ; pp. 105-221. Available online: https: / / e-book.business /itil-foundation-4th-edition/ (accessed on 25 June 2021).

36. Guetterman, T.C.; Fetters, M.D. Two Methodological Approaches to the Integration of Mixed Methods and Case Study Designs: A Systematic Review. Am. Behav. Sci. 2018, 62, 900-918. [CrossRef] 